and AN than between SON and words corresponding to parts of the body. Nevertheless, a detectable stimulus change may be expected to lead to a generalization decrement irrespective of Ss' reported awareness of the change. This generalization decrement, which would lead to a loss or change in set, may also lead to attention arousal. If such distinctive items increase a person's attention, then an isolated item may be learned more rapidly and to a greater degree than nonisolated items.

If the above conclusions were based only on the present results, they might be unwarranted because the authors used a reversed proactive transfer paradigm in which a shift in material was confounded with potential differences in difficulty of different types of material. The above conclusions appear valid, however, because large recall increments following symbolic shifts from both SON to AN and AN to SON have been reported (Brodie \& Lippman, 1970), and Reutener (1969) has independently confirmed these findings. Furthermore, Wickens (1970) indicated that symbolic shifts produce equal recall increments compared to shifts between taxonomic or semantic classes.

\section{REFERENCES}

ADAMS, J. A. Human memory. New York: McGraw-Hill, 1967.

ADAMS, J. A., THORSHEIM, H. I., \& McINTYRE, J. S. Item length, acoustic similarity, and natural language mediation as variables in short-term memory. Journal of Experimental Psychology, 1969a, 70, 39-46.

ADAMS, J. A., THORSHEIM, H. I., \& MCINTYRE, J. S. Short-term memory tasks.

\title{
The repeated use of mnemonic imagery
}

\author{
P. E. MORRIS and R. L. REID \\ University of Exeter, Exeter, England
}

Can the same mnemonic system be used repeatedly without deterioration in performance through interference? Ss used a "peg-word" system to memorize a single list of 10 nouns in different orders. No decline in performance was found. A control group improved on successive trials but at all times recalled less than the mnemonic group.

The "peg-word" system, part of the stock-in-trade of mnemonic experts, is intended to facilitate memorizing lists of items. As a preliminary to one method, a jingle associating objects with ordinal positions is mastered (one is a bun, two is a shoe, ... ten is a hen). To memorize a list of items, the first is visualized in association with a bun, the second with a shoe, and so on. Instructions usually require the learner to conjure up bizarre mental pictures including movement, e.g.
Psychonomic Science, 1969b, 15, 77-78.

BRODIE, D. A.. \& LIPPMAN, L. G. Symbolic and size shifts in short-term memory tasks. Psychonomic Science, 1970, 20, 361-362.

ERICKSON. R. L. Relational isolation as a means of producing the von Restorff effect in paired-associate learning. Journal of Experimental Psychology, 1963, 66, 111-119.

GUMENIK, W. E., \& ROSSMAN, F. A perceptual isolation effect in short-term memory. Psychonomic Science, 1970, 19, 98-99.

JOHNSON, W. L., \& CHAMBERLIN, C. M Semantic and acoustic similarity and their effects on short-term retention. Psychonomic Science, 1970, 19, 217-218.

LOESS, H. Short-term memory, word class and sequence of items. Journal of Experimental Psychology, 1967, 74, 556-561.

LOESS, H. Short-term memory and item similarity. Journal of Verbal Learning \& Verbal Behavior, 1968, 7, 87-92.

NEISSER, U. Cognitive psychology. New York: Appleton-Century-Crofts, 1967.

NORMAN, D. A. Memory and attention. New York: Wiley, 1969.

REUTENER, D. Background, symbolic and class doctoral dissertation, Ohio State University, 1969.

TURVEY, M. T. Analysis of augmented recall in short-term memory following a shift in connotation. British Journal of Psychology, 1968, 59, 131-137.

WICKENS, D. D. Encoding categories in short-term memory. Paper presented at American Psychological Association meeting, 1968.

WICKENS, D. D. Encoding categories of words: An empirical approach to meaning. Psychological Review, 1970, 77, 1-15.

WICKENS, D. D., \& ECKLER, G. R. Semantic as opposed to acoustic encoding in STM. Psychonomic Science, 1968, 12, 63.

WICKENS, D. D., \& SIMPSON, H. K. Semantic versus phonetic encoding in short-term memory. Paper presented at Midwestern Psychological Association meeting, 1968. shift in short-term memory. Unpublished

One might suspect that an unusual but easily grasped method could give good results on a first trial with naive Ss, but that performance would deteriorate rapidly, the buns and shoes becoming encrusted with interfering associations. Psychologists have learned to fear proactive inhibition (Underwood, 1957; Postman, 1961). The writers of memoryimprovement books are optimistic on the whole, but there are some differences of opinion among them. Lorayne (1958) assumes that the same peg-word can be used without restraint, while Weinland (1957) is apprehensive about interference, and Hamilton (1948) advises his readers to limit the frequency of use to no more than once per day.

Some evidence is available from an experiment by Bugelski (1968). Six lists of common nouns were memorized and tested one after the other in a single session. $\mathrm{E}$ group Ss were told how to use the peg-word jingle. C group Ss were simply told to learn. The mnemonic group was significantly superior, maintaining an almost perfect performance throughout the six lists. The control group zig-zagged from high to low performance on successive lists, improving overall from first to last.

In Bugelski's experiment each $\mathrm{S}$ was free to go at his own pace and so would have been able to compensate for increasing interference by lengthening the time taken per item. No data are reported on this point. In the following experiment each item was exposed for a fixed duration and a more stringent test of interference was attempted. Where response learning is minimal, an $\mathrm{A}-\mathrm{B}, \mathrm{A}-\mathrm{Br}$ arrangement, in which the response items of the first list are reallocated to different stimuli in the second list, can be expected to produce greater interference than when the responses of the second lists are new items (McGovern, 1964; Kausler, 1966). Bugelski used a different set of nouns as responses for each list. Following the $\mathrm{A} \cdot \mathrm{B}, \mathrm{A} \cdot \mathrm{Br}$ paradigm, we used the same 10 nouns re-paired with new numbers. Thus, while Bugelski's Ss had to associate six nouns with each position in the list, ours had to associate the same noun with a different position for each of six tests of recall.

\section{METHOD}

image of a tiny car in motion with huge buns as wheels.

Although techniques of this kind figure in William James' The Principles of Psychology (1890), they appear to have escaped empirical investigation until recently. Reports by Miller, Galanter, \& Pribram (1960), Hunter (1964), and Bugelski, Kidd, \& Segmen (1968), among others, have now shown the claims of the mnemonic experts to be well founded. 
Table 1

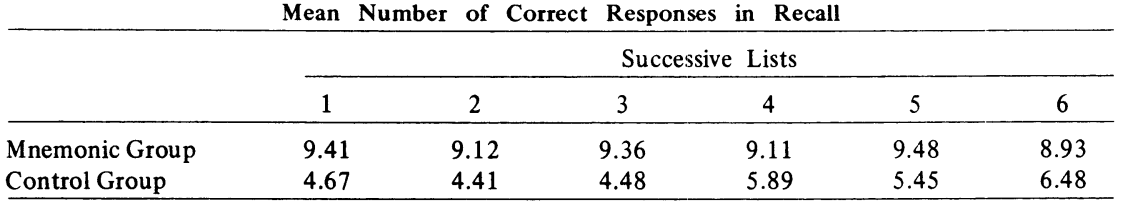

were prepared for testing retention. All tests were recorded by a male voice.

The Ss were told that their task was to memorize each of the six lists in turn, that the items of each list would be presented once only, and that they would be required after each list to respond on hearing the numbers out of sequence by writing the corresponding nouns. The lists were presented at a rate of one number-noun pair every $8 \mathrm{sec}$. A pause of $30 \mathrm{sec}$ followed each list and then the test stimuli (numbers alone) were presented, also at 8 -sec intervals. The test papers were collected and the new learning list started within $2 \mathrm{~min}$.

Ss were tested in groups. The 27 control Ss were simply told what they had to do and were asked at the end of the experiment to describe their methods, if any. The 27 members of the mnemonic group began by reciting, "One is a bun, two is a shoe, three is a tree, four is a door, five is a hive, six is sticks, seven is heaven, eight is a gate, nine is a mine, ten is a hen." This was written on a blackboard and remained in view throughout the experiment. It took only a few minutes before they were satisfied by self-testing that they knew the rhyme. They were told how to use the peg-words by forming mental pictures linking each peg-word to the item with the same number in the list. The picture was to include as much movement as possible and to be as ridiculous as possible. Once clearly formed, each picture was to be dismissed and not recalled until required in the test, when they were assured that it would return. Given some examples, no $\mathrm{S}$ found difficulty with the method.

At the end of the experiment Ss were questioned on their performance.

$$
\text { RESULTS }
$$

The mean recall scores of the two groups are shown in Table 1.

By analysis of variance the difference between mnemonic and control groups was highly significant $(\mathrm{F}=118.34, \mathrm{df}=1 / 52$, $\mathrm{p}<.0001)$. There was a significant trials effect $(F=3.20, d f=5 / 260, p<.01)$, and a significant interaction between trials and groups $(F=5.68, \mathrm{df}=5 / 260, \mathrm{p}<.001)$. Inspection of Table 1 suggests that the trials effect and the interaction are the result of an improvement in the performance of the control group without change in the performance of the mnemonic group. This was confirmed by further analysis. While the mnemonic group showed no change in performance with trials $(F=1.22, \mathrm{df}=5 / 130, \mathrm{p}=.304)$, the control group improved significantly $(F=5.42, d f=5 / 130, p<.001)$. Scheffé's test on the group means showed that the mnemonic group recalled more than the control group on all six trials $(p<.05)$.

The errors and omissions of both groups were analyzed. The mnemonic group made more errors in recalling items from the first half of each list (1-5, 80 errors; 6-10, 45 errors; $z=3.04, p<.003)$, while the control group made more errors in recalling the second half $(1-5,319$ errors; $6-10,454$ errors; $z=4.82, p<.001)$. Analyzed in terms of the order in which items were more errors in the second half of each test. (Mnemonic group, 1-5, 38 errors; 6-10, 87 errors; $z=4.29, p<.001$. Control group $1-5,351$ errors; $6-10,422$ errors; $z=2.55$ $\mathrm{p}<.01$.)

The control group reported a variety of methods of learning, most Ss changing method at least once. Three control Ss who said they had visualized objects with numbers had better scores than the rest of their group (Mann-Whitney $U=1$, $\mathrm{p}<.01)$.

The results demonstrate that instructions to use the mnemonic method have a beneficial effect on recall. Recent experiments (Paivio, 1969) support the view that the process of visualizing, as such, makes for better recall than does verbal association provided the words to be remembered are "concrete." The simple hypothesis that the method would succumb to proactive inhibition after an recalled during tests, both groups made initial success was not confirmed. The same set of peg-words could be used over and over again without detriment, even in the adverse conditions of the experiment.

Questioned at the end of the experiment, all of the mnemonic group claimed to have followed the method as instructed. Opinion was divided on whether or not the learning task seemed to become more difficult as the experiment progressed, and only two had tried to use some method of keeping the lists separate.

The improvement of the control group calls for an explanation. The Ss of this group were free to test and to change their methods, and their reports suggest that this is what they did. By contrast, the mnemonic group were instructed to use only one method and claimed to have done just this. The control group therefore had a greater opportunity of learning-to-learn than did the mnemonic Ss, whose performance was, in any case, too near the maximum to allow for much improvement. No evidence was found for a zig-zag performance on successive lists as reported by Bugelski (1968).

\section{REFERENCES}

BUGELSKI, B. R. Image as a mediator in one-trial associate learning. Journal of Experimental Psychology, 1968, 77, 328-334.

BUGELSKI, B. R., KIDD, E., SEGMEN, J. Image as a mediator in one-trial paired associate learning. Journal of Experimental Psychology, $1968,76,69-73$.

HAMILTON, F. S. Mastering your memory. New York: Grammercy, 1948.

HUNTER, I. M. L. Memory. Hardmondsworth Penguin, 1964.

JAMES, W. The principles of psychology. New York: Holt, 1890.

KAUSLER, D. H. Readings in verbal learning. New York: Wiley, 1966.

LORAYNE, H. How to develop a super power memory. Preston: Thomas, 1958.

McGOVERN, J. B. Extinction of associations in four transfer paradigms. Psychological Monographs, 1964, 78(16, Whole No. 593).

MILLER, G. A., GALANTER, E., \& PRIBRAM, $\mathrm{K}$. H. Plans and the structure of behavior. New York: Holt, 1960.

PAIVIO, A. Mental imagery in associative learning and memory. Psychological Review, 1969, 76, 241-263.

POSTMAN, L. The present status of interference theory. In C. N. Cofer (Ed.), Verbal learning and verbal behavior. New York: McGraw-Hill, 1961. Pp. 152-179.

UNDERWOOD, B. J. Interference and forgetting. Psychological Review, 1957, 64, 49-60.

WEINLAND, J. D. How to improve your memory. New York: Barnes \& Noble, 1957. 